\title{
Shifting the Focus to Student Learning: Characteristics of Effective Teaching Practice As Identified by Experienced Pre-service Faculty Advisors
}

\author{
Nancy Maynes \\ Nipissing University \\ Blaine E. Hatt \\ Nipissing University
}

\begin{abstract}
Cochrane-Smith and Power identify trends in teacher education programs with some relating to heightened teacher accountability for students' learning. In this paper we provide a model that identifies characteristics believed to be critical elements related to a teacher's conceptual focus shifting from an emphasis on their teaching to their students' learning and we have grounded these characteristics in current educational research. Through focus group inquiry, we have identified those teacher characteristics thought to account for effective teaching practice. These characteristics include: a professional growth perspective, passion and enthusiasm for the content, pedagogical content knowledge, a rich instructional repertoire of strategies, awareness of assessment for, as, and of learning, ability to read the body language of the learner, caring classroom management strategies, and instructional efforts (e.g., social justice). Our research data provide a conceptual framework for further study.
\end{abstract}

Keywords: learning processes/strategies, teacher induction, teacher education-preservice

Nancy Maynes is Associate Professor in the Schulich School of Education at Nipissing University.

Email: nancym@nipissingu.ca

Blaine E. Hatt is Assistant Professor in the Schulich School of Education at Nipissing University.

Email: blaineh@nipissingu.ca

Brock Education, Volume 22, No. 1, Fall 2012, 93-110 


\section{Objectives}

Research calls for accountability measures that emphasize the impact of teacher preparation programs and pathways on student learning outcomes (Cochran-Smith, Gleeson \& Mitchell, 2010; Noell \& Burns, 2006) or evidence of teacher candidate learning outcomes from their programs (Pecheone \& Chung, 2006). Cochrane-Smith and Power (2010) identify trends in teacher education programs, which are related to heightened teacher accountability for students' learning. Recent research shows that the relationships between teachers and their students have many complex impacts on students (Roorda, Koomen, Spilt, \& Oort, 2011); however, the complexity of factors that may influence students' learning outcomes, when viewed from this perspective, renders a linear assessment of influences futile.

Alternatively, we envision students' learning potential from the perspective of imaging of the teacher. If the teacher has the skills and dispositions to focus on student learning, we believe that the teacher's instructional actions support improvements in student learning. To provide a background for this belief, we identified the characteristics of effective teachers as they emerged from our focus group discussions with experienced pre-service teacher faculty advisors.

\section{Perspectives and Theoretical Framework}

Pre-service teacher preparation programs attempt to expose pre-service teachers to the practices, accreditation requirements, and the continuous climate of performance assessments that characterize the profession of teaching. Various jurisdictions do this through programs that have a variety of structures and timelines. However, virtually all programs include an apprenticeship element or practicum component, sometimes supported by ongoing mentorship through individual or small group connections with a faculty advisor as in the case of on-line chat groups. However, teacher preparation programs acknowledge the limitations of time as a factor in determining the extent to which pre-service teachers can be prepared for the complex realities of professional responsibilities in a classroom. Graduates of all teacher preparation programs require and receive further support in their professional preparation after graduating from their program. The hiring practices of a school jurisdiction, the induction processes used by employers, the novice teacher mentoring supports available to new teachers within a school, the on-going professional development available to teachers during employment, and the career trajectory supports made available to experienced teachers are all part of the preparation of teachers to manage the challenging task of ensuring student learning.

We believe that a critical part of maximizing the impact of all of the supports available to teachers throughout their careers needs to be focused on a single shift in teachers' thinking: the shift from focusing on their teaching toward focusing on their students' learning. On a minute-to-minute basis in the classroom, teachers must make instructional decisions. Teachers need to learn to make each instructional decision on the basis of its impact on students' learning (Abbot, 1991; Darling-Hammond, 1992). Increasingly, teachers have been called upon to demonstrate public accountability by showing the impact of their instructional decisions in terms of student performance data (Amos, 2012; Stratham \& Ware, 2001). While efforts to collect student performance data in the classroom may be authentic and focused on big ideas, enduring understandings, 
and holistic goals that influence attitudes and beliefs along the knowing/doing/being continuum, the measurement of instructional impact also serves other masters. Public accountability requirements have resulted in practices that reflect the accumulation of hard data that can be reported in absolute numbers to address public confidence in the educational system (Amos, 2012).

Testing is often used to amass data that may include high stakes (pass/fail) single event opportunities for students to demonstrate learning. Teachers are faced with the contradiction about the purposes and processes of assessment and the types of data that appear to be given status and value as evidence of student learning. Consequently, they are receiving confusing messages about their professional role. Authentic assessment foci direct teachers' attention toward the learning. Accountability focused assessments direct attention toward the teacher. This contradiction makes the professional maturation of a teacher more difficult than it should be and delays or derails the critical shift in teachers' growth required to ensure that teachers' instructional decisions are filtered through their ability to impact students' learning (Amos, 2012; Henry, Bastian, \& Fortner, 2011).

The continuum of teacher preparation needs to be focused on maximizing through various career stages its' contributions to the professional maturity of the teacher (Figure 1). The teacher growth that is the result of pre-service learning, hiring practices, novice teacher induction, in-service professional development, and career trajectory choices needs to be coordinated to provide a single clear message about the goal of all instructional efforts.

\section{Figure 1.}

\section{The Various Stages of Professional Growth to Teachers' Professional Maturity}

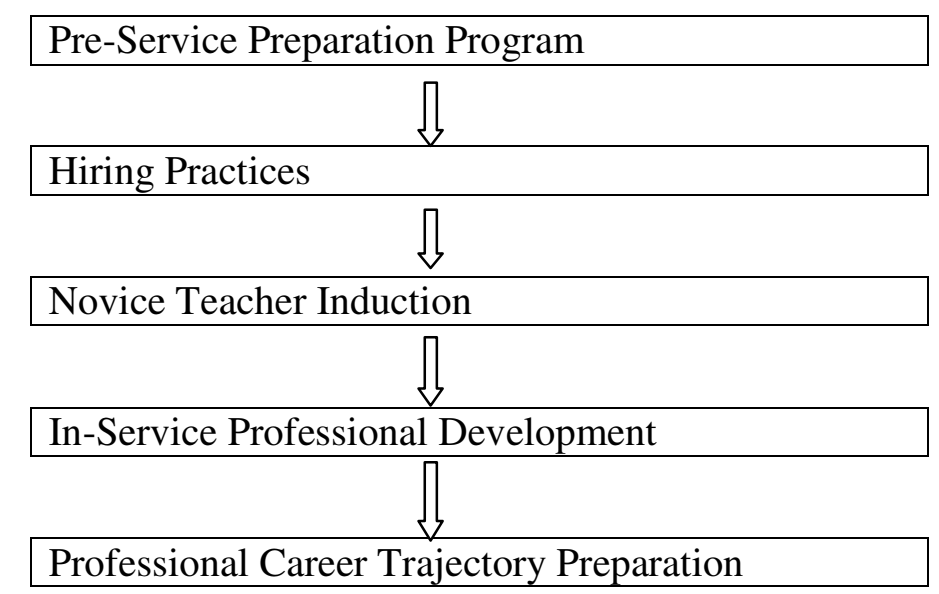

When we examine teacher effectiveness by gauging student learning, findings show that student learning plateaus after the teacher's first three years in the profession (Henry, Bastian, \& Fortner, 2011). This trend indicates that we should focus considerable attention on optimizing practices focused on student learning in the pre-service preparation of teachers and in the early years of their professional work. Early career focus should help novice teachers make a strong shift toward student learning. If this is 
done, the effects of plateauing could have minimal effect on students' learning because the teacher would already be focused on ensuring learning as a filter for their professional practice. The teacher would understand the characteristics necessary for their professional effectiveness.

Our focus of investigation in Stage 1 of our research was What are the elements that characterize a teacher's shift in focus from their teaching to students' learning? In re-conceptualizing our vision of teacher preparation as a continuum of supports that focus all efforts on the professional goal of improving students' learning, we needed to ask ourselves what existing, or new, theory supports this re-conceptualization. Theory provides the capacity to conceptualize phenomena in sophisticated ways (Trier, 2009) and drawing from disparate sources strengthened our efforts, as researchers, to identify a theory that would support professional growth designed to increase student learning. In understanding the elements that create or contribute to the shift in teachers' focus from individual teaching to students' learning, we, as pre-service teacher educators and researchers, can support teachers' professional growth more effectively (Chen \& Rossi, 1983; Donaldson, 2007; Rogers, Hacsi, Petrosino \& Huebner, 2000; Coulter, 2010). And, if we can identify the elements that characterize the shift in teachers' focus and that contribute to their professional maturity, we have a unique opportunity to align the various stages of their professional growth to attain high levels of student achievement. Naming a theory makes it more readily accessible; we, therefore, call the theoretic diagram that resulted from Stage 1 of our study Professional Shift Theory (pst).

Before we turn our attention to identifying how we went about conceptualizing this shift in professional focus for teachers, it is necessary to address the role of the apprenticeship and practicum experiences that are a universal element of teacher preparation. Induction mentorship is also becoming increasingly common and even legally mandated in some jurisdictions as a stage of professional preparation of new teachers. Teachers are more likely to recognize and address substantive changes in their own professional performance if they have access to the professional practices of other teachers (Coulter, 2010). The value of having the professional guidance of a mentor teacher focused on assisting the novice teacher in their desired learning is self-evident. If everyone is working toward the same learning goals for the pre-service teacher in their preparation practica and for the novice teacher in their mentorship, then the desired outcomes are more likely to be achieved. If teacher associates, faculty advisors, and mentors understand the common elements to be addressed in the pre-service and novice teacher's learning, they have a better chance of ensuring that such learning occurs by avoiding conflicting messages about priorities, and by optimizing the learning time during practica and in-service professional development. The vision shared by stakeholders who have responsibility for the professional growth of the pre-service teacher and the novice teacher becomes the direction and that direction becomes the filter for learning efforts. If apprenticeship opportunities are further aligned with the other aspects of teacher preparation (Figure 1), the impact is optimized and the priorities of the profession are clear to all involved. The model we provide in Figure 2 presents a vision for professional characteristics that could inform each stage of a teacher's career growth.

Our method of inquiry and the findings in Stage 1 of our research provide an expanded vision of the elements that we theorize are part of the professional shift in thinking that is required of teachers to reach the end goal of optimizing student learning. 
The conceptualization of this vision (Le Cornu \& Ewing, 2008) is presented in Figure 2 in the results section of this paper.

\section{Methods of Inquiry}

This paper outlines the outcomes of the first stage of a three-stage study. During this stage of the study we isolated the characteristics of effective teachers that represent a shift in teachers' professional focus from their teaching to focusing on their students' learning as identified by a focus group of experienced faculty advisors. During the second stage of the study, we will work with various jurisdictions that include a faculty of education and coterminous school boards to identify hiring, induction, and in-service practices that support the conceptualized shift in teachers' professional focus. In the third and final stage, we will work with personnel in these jurisdictions to strengthen the vision and focus of support efforts provided along the teacher professional growth continuum to ensure a sustained and clear focus on professional growth that supports students' learning.

As stated above, our research purpose in Stage 1 was to isolate the elements of the professional shift in teachers' focus from teaching to a focus on students' learning. In doing so, we were able to identify the characteristics of effective teachers that were valued by experienced faculty advisors. In our Faculty of Education, there are 70 full time Faculty members. Among this group were 7 full time faculty members who had, as part of their workload, the role of Faculty Advisors responsible for visiting pre-service teachers in classrooms to lend support and to evaluate their practice teaching. We felt that faculty advisors working with pre-service teachers as both instructors in their professional preparation programs and as mentors/evaluators within the context of their practicum experiences were in an ideal position to provide academic and professional insights on pre-service teachers. The group of seven faculty members who served in these conjunctive roles was invited to participate in a focus group inquiry. All seven faculty members accepted the invitation to participate. Research ethics approval was sought and given to interview and transcribe data from the focus group sessions for the purpose of identifying the elements that were thought to contribute to a teacher's professional focus on students' learning.

In focus group discussions, the group of seven faculty advisors engaged in a conversational interview with appropriate open-ended prompts being used to encourage discussion. During three focus group meetings, participants were directed to consider the elements of practice and provide examples they had observed that would provide evidence of pre-service teachers who had made a professional shift in their thinking from focusing on their teaching to focusing on students' learning. During these meetings, researchers made audio-recordings of the discussions and made summative notes of key points. Following each meeting, the researchers transcribed recordings and examined data for recurring themes and observations (Cresswell, 2002). Transcriptions were presented to focus group participants at each successive meeting for the purposes of verification, clarification, and member checking.

As recurring themes became evident in transcriptions and were supported by follow-up discussions, a saturation of ideas was reached. Ideas were repeated and reinforced with further examples from the experience(s) of various participants. The decision was made to capture the main points of discussions in a diagram that would 
represent the elements of teachers' conceptual shift in focus and that would provide ease of access for a wider audience. An initial diagram was developed and the transcripts were then rechecked to ensure that the elements included in the diagram were also in evidence, to the point of saturation, in the dialogue of participants. The resulting diagram was revised to include connections among ideas and to make the interrelated concepts more accessible. A clear understanding of interrelated concepts was necessary to move the study into Stage 2 and to provide the background concepts of the diagram for a broader audience of educators.

The resulting diagram has the value of capturing program theory in an easy-toaccess and understandable format. It also provides a conceptualization of how a program might operate to ensure its efficacy. Program efficacy is achieved by conceptualizing the influences on program functions and by identifying their potential impacts (Chen \& Rossi, 1983; Donaldson, 2007; Rogers, Hacsi, Petrosino \& Huebner, 2000; Coulter, 2010). An additional and critical advantage of the conceptual diagram is to provide a filter for the efforts that should not become central aspects of the limited resources in time and funding available along the teacher maturation continuum (Figure 1).

\section{Results: Elements of Professional Teachers' Focus on Student Learning}

In this study, all participants perceived that a shift in focus takes place within many preservice teacher candidates as they begin to develop conscious competence in their profession. As the pre-service teachers begin to focus on students' learning, observers in the faculty advisor role could see the shift in the pre-service teachers' professional practice. This shift underlies all of the characteristics of conscious competence.

This study started with the premise that during their tenure as teachers, continuous growth and maturation as a professional will result in a shift in professional focus away from teaching actions and toward students' learning. All participants in the focus group discussions had experience as classroom teachers, faculty of education professors engaged in teacher preparation programs, and faculty advisors involved in practicum supervision, including mentoring. All participants unanimously agreed that this shift in teachers' focus is a characteristic that reflects the teacher's increasing professional maturity. Their participation in the focus group discussions evidenced their willingness to examine the impact of specific activities on performance and their belief in the necessity of improvements in teaching as a professional characteristic (Allen, 2004). All participants agreed that a clearer conception of the elements that contributed to a professional focus on learning was timely and necessary as a filter for program improvement in a pre-service context. Participants also believed that certain actions and dispositions are critical to creating a focus on students' learning. In the program change process, a positive program change would include application of a consistent vision of the elements present when teachers focus on learning (Maynes \& Hatt, 2011).

The conceptions that resulted from Stage 1 of our research helped us frame the next two stages of this study which will focus on student learning as a function of teaching (Phelan, 2009) rather than as a function of students' efforts to learn. Stages 2 and 3 will help us to see teaching as "a site of possibility" (Phelan, 2009, p. 106) capable of effectively influencing student learning. The elements of the shift in focus towards focusing on students' learning are presented here, in Figure 2, as developed through our focus group interactions (Figure 2). 
Figure 2. Professional Shift Theory (pst)

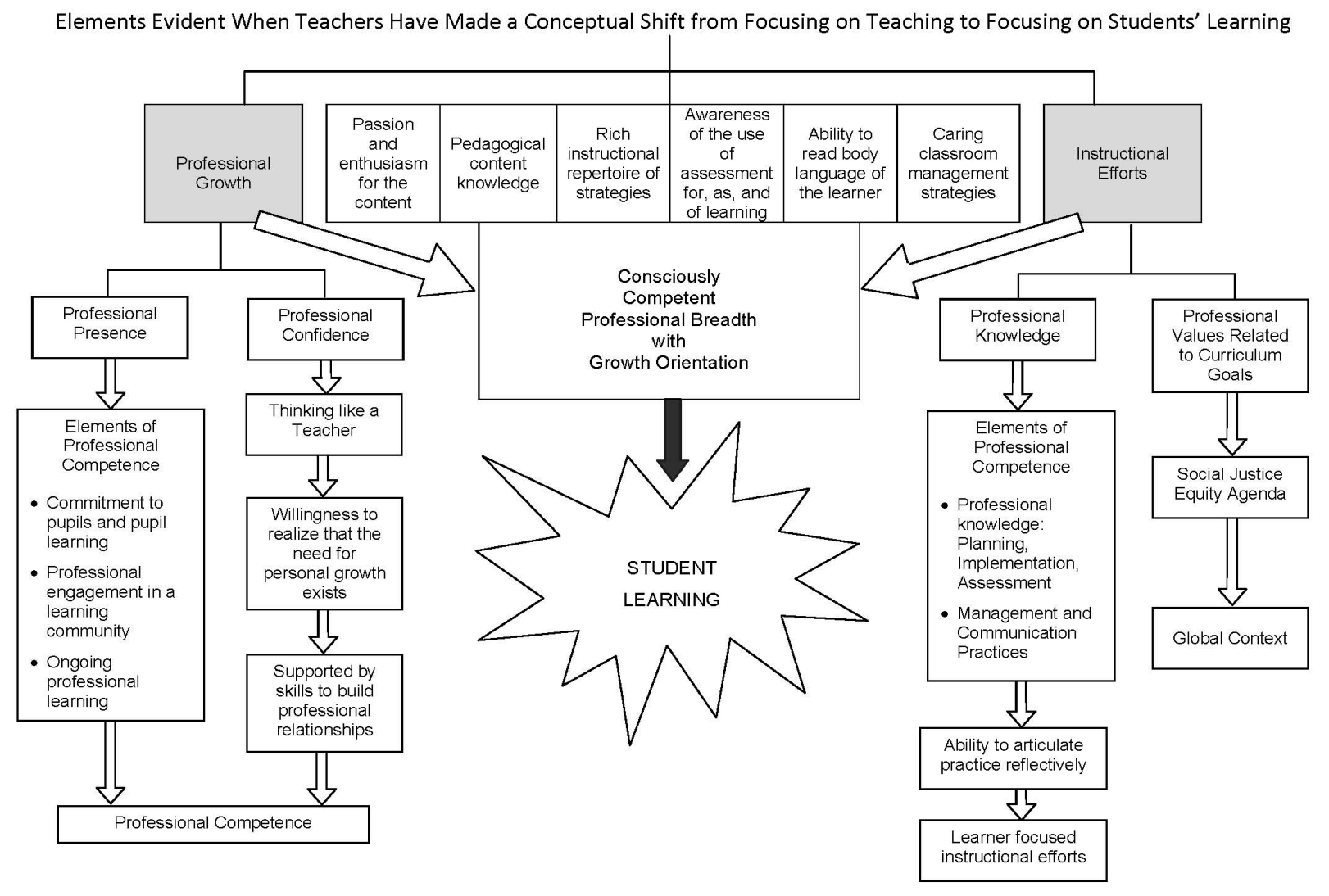

To create this schematic, data collection, analysis, and conceptual formulation were connected in a reciprocal and recursive manner. Examination of emerging themes during the different meetings provided opportunities for participants to guide analysis and facilitate the process of diagramming. The diagram was subjected to the four requirements identified by Strauss and Corbin (1990). Specifically, 1) the fit between the diagram and the 'shift in conception' phenomenon, including its evolution from diverse data and its adherence to the common reality of experienced faculty advisors; 2) the ability of the diagram to support understanding of this shift in thinking for teachers; 3 ) the applicability of the conceptualizations in this diagram to broad contexts; and 4) the potential of the diagram to provide direction about its applicability and to support reasonable action related to teachers' professional growth. The following paragraphs explain the elements represented in this diagram and anchor conceptions in previous educational research.

\section{Understanding the End Result: A Consciously Competent Professional}

The data contributes to the major theme of a consciously competent professional, and six contributing attributes necessary to be defined in this manner, along with supporting 
skills, attitudes, and dispositions. The main element in this shift was identified as the conception of a consciously competent professional, with professional and instructional breadth and a growth orientation. This conception is evident in the research literature and in professional resource books about teaching (Boyatziz, 1982; Brundrett \& Silcock, 2002; Leat, 1993). The consciously competent professional's focus on instructional and professional actions would make improved student learning a priority. According to the data, the consciously competent professional teacher, who focuses on student learning, would require a cadre of attributes to support instructional efforts and maintain a professional growth orientation (Clarke \& Hollingsworth, 2002; Fenwick, 2001). These attributes include: 1) passion and enthusiasm for the subject content, 2) pedagogical content knowledge, 3) a rich instructional repertoire of teaching strategies, 4) awareness of the various productive ways that assessment data can be used, 5) sophisticated ability to read the body language of the learner, and 6) caring classroom management strategies.

1) Passion and enthusiasm for the subject matter provide a platform for engaging students' interest (Day, 2004; Hobbs, 2012). By demonstrating this passion and enthusiasm, the teacher motivates and provides reasons for students to attend to new ideas. Teachers develop engaging strategies when they have an interest in a topic. Students benefit from having high levels of interest stimulated through meaningful engagement (Meador, 2012 Online; Mroz, 2008). Both positive and negative teacherstudent relationships during learning have been shown to have medium to large impacts on students' engagement (Roorda, Koomen, Spilt, \& Oort, 2011).

2) Pedagogical content knowledge is a level of comfort and familiarity with a topic that allows teachers to engage examples and non-examples; to explain, clarify, and expose students to complex opportunities to consider consolidations and applications (Shulman, 1987; Van Dreil \& Berry, 2012). Consolidation and opportunities to apply learning support students' internalization of new ideas. This attribute allows teachers to anticipate common misconceptions and provide learners with opportunities to examine and consider various aspects and perspectives about a topic. Strong pedagogical content knowledge allows teachers to differentiate effectively because they can provide variations within the scope of central ideas to respond to students' interests, learning profiles, prior learning, and readiness (Tomlinson et al, 2009). Pedagogical content knowledge can be enriched by engagement in professional self-examination in professional learning communities (Vescio, Ross, \& Adams, 2008).

3) A necessary attribute of teachers who focus on students' learning is a rich instructional repertoire of strategies for use during the instruction, consolidation, and application components of lessons (Garmston, 1998; Goodyear, 1991). Being able to vary approaches allows teachers to provide learning opportunities that maximize students' ability to learn through their preferred learning styles (Maynes, Julien-Schultz \& Dunn, 2010; Maynes \& Julien-Schultz, 2011). The ability to select direct instruction through modeling, or to choose from among a rich variety of indirect approaches such as projectbased learning, cooperative learning, web quests, or inquiry, provides both exemplar exposure and experiences to support internalization of central concepts (Maynes \& Straub, 2010). 
4) Awareness of the possible uses of assessment is an essential attribute of effective teachers. Teachers who focus instructional efforts on students' learning arrange opportunities to gather assessment data for, as, and of learning (Davies, 2012; Earl 2006; Earl, 2008; Tomlinson, 2007) and include assessment that is embedded and non-intrusive. The learner has a role in self- and peer-assessment. Learning and assessment of the learning become seamless.

5) Teachers who focus on students' learning are able to read the body language of the learner (Craig, Graesser, Sullins, \& Gholson, 2004). This body language provides early signals that learning is happening or that the student's grasp of the learning is problematic (Coulson, 2004). The ability to understand the body language of the learner allows teachers to adjust learning opportunities (reflection-in-action) and remain sensitive to the potential for adapting content, processes, or products to improve learning (Conati, 2002).

6) Caring classroom management strategies are essential to ensuring the preeminence of learning as a focus in the classroom (Noddings, 2002, Hatt, 2005, Hatt, 2008). Through the appropriate, supportive, and proactive use of rules and routines in the classroom (Breaux \& Whitaker, 2006), teachers who focus on students' learning ensure that learning time is optimized, that the focus on learning is a central filter for all decisions, that learning happens in responsive and flexible environments, and that respect for individuals is the guiding premise (Charney, 2002).

All six of these attributes must be present for a teacher to be considered a consciously competent professional. These basic attributes are expanded and enriched by professional presence and personal professional confidence.

A teacher's professional presence in the classroom projects a sense that the teacher is in charge, has a direction, and is guided by a sense of purpose. Elements of professional competence that relate to a teacher's professional presence include: their commitment to students and their learning, their engagement in a professional learning community through cooperative professional growth, and their commitment to ongoing professional learning (Vescio, Ross, \& Adams, 2008). Conscious competence is deepened by the person's ability to think like a teacher. This includes their ability to focus efforts on issues and strategies that can impact students' learning and expanding their conceptual repertoire of professional knowledge to encompass concepts that enable the operation of effective practice (Kameenui \& Carnine, 1998: Killen, 2006; Orlich et al, 2010). Being open to professional growth is critical to the teacher's ability to expand their realization of the need for personal growth and extend their capacity and willingness to grow. Professional growth is seen as a function of the desire to improve student learning. Recent research (Henry, Bastian, \& Fortner, 2011) reports the tendency of teacher growth, as measured by increases in their students' learning, to plateau after their third year of teaching. However, professional growth that is supported by the interpersonal skills to build professional relationships may offer support for continuous growth that is reflected in the teachers' actions and measureable in the students' achievement data. These supports may further professional growth through cooperative stimulation and constructive peer mentoring and collaboration. Professional competence is the outcome of the coexistence of professional presence and professional confidence. 
Professionally competent breadth with a growth orientation is supported by the teacher's instructional efforts (Maynes, 2012) and the cadre of skills they develop to support these efforts. Instructional efforts are enriched by the teacher's professional knowledge and their professional values in synchronization with curriculum goals. Elements of the teacher's professional knowledge include their knowledge of effective curriculum planning, implementation, and assessment, as well as their management and communication practices with related stakeholders such as students, parents, guardians, support agencies, care providers, administrators, and policy makers. In a learner-focused environment, the teacher's ability to reflect and articulate their professional practice is a key to the ability to use, improve, expand, and actualize practice when needed. When the teacher can name and describe what they do, they have the advantage of reflective and responsive use of what they do. Reflection allows the teacher to understand the impact of specific actions in an instructional context on specific outcomes in student learning. When all instruction is focused on what the student is learning in relation to the time and effort spent, an economy of effort characterizes the instruction. The instruction becomes responsive and learner focused.

The cadre of specific skills and a set of professional values that are synchronized to the current curriculum goals of the jurisdiction support instructional efforts. Each curriculum guideline identifies knowledge, skills, and values that are contextualized in the expected learning outcomes of the jurisdiction. The teacher who has made the conceptual shift toward focusing on students' learning will be able to understand, teach, and exemplify the values that are espoused in a guideline. These values will often relate to the big ideas or enduring understandings of the subject. Additionally, these values reflect the commonly espoused values of the community and evolve in the context of general social awareness. These values will include and are encompassed by a social justice equity agenda and relate to the global context. The professional values related to curriculum goals that are held by the teacher will be reflective of the inclusive social goals of the era. They will be understood and modeled for students in the classroom context. The classroom norms of behaviour are used to model and practise the predominant social norms of the society.

\section{Conclusions}

The diagram (Figure 2) represents the conceptual shift at end point. The elements represent the attributes that require development in order to make the conceptual shift from focusing on teaching to focusing on student learning. This shift in focus is characteristic of effective teachers.

The schematic can be used broadly in pre-service and in-service contexts to guide professional discussions, growth plans, professional evaluations, and school improvement efforts. It has the potential to provide direction about reasonable actions related to teachers' professional growth along the continuum from pre-service to professional maturity. In addition, the conceptual diagram allows researchers to consider the potential impact of situational factors such as the curriculum, work factors, resource limitations, space constraints, the learning setting, the interest of the students, classroom disruptions, and the intensity of reform on student learning (Kennedy, 2011). It also allows educators to consider how "fundamental attribution error" (Kennedy, 2011, p. 597) may lead to 
assignment of some effects to the wrong causes. The details of the conceptual diagram provide specific and particular direction about theorized attributes that may promote learning. Such details provide structure for further investigation.

If this schematic, or conceptual diagram, is used to inform the next transition in teaching from the pre-service program to hiring, hiring practices could be anticipated to change significantly. For example, interview practices might include examination of the candidate in a classroom context to determine the extent of their focus on students' learning. Additionally, interview questions might change in focus. Performance based questioning that attempted to determine the candidates' skill from anecdotes about past experiences would provide indicators of the candidate's ability to sustain a focus on learning. Questions could be generated directly from the conceptual diagram and focus on the main elements of the teacher's professional knowledge and dispositions, their professional growth, and instructional efforts, beliefs and commitments. These questions could be designed to target the outcome of student learning. The conceptual diagram provides a framework for interviewers to filter interviewee responses to questions; the "look-fors" of the answers. This extension is the focus of Stage 2 of this research study, now underway. Similar applications could be anticipated to support design of induction programs for novice teachers, in-service programs, and career trajectory paths.

\section{Educational Significance}

This conceptual diagram was designed for two purposes. First, it anticipates teachers' instructional actions with corresponding positive changes in students' performance when the program elements at the pre-service, hiring, novice teacher induction, in-service, and teacher career trajectory paths are considered (Coulter, 2010; Elsmore, Peterson \& McCarthy, 1996;). This investigative focus is timely as it aligns with a very large metaanalysis of previous research identifying correlated impacts on students' learning (Roorda, Koomen, Spilt, \& Oort, 2011). Second, the diagram is the schematic that informs Stages 2 and 3 of our research.

Many current in-school professional development efforts involve professional learning communities that focus on student achievement, and examine ways to improve student achievement (Abbot, 1991; Darling-Hammond \& Snyder, 1992; DarlingHammond \& Goodwin, 1993; Little, 1990; Strathan \& Ware, 2001; Coulter, 2010; Grossman, Wineburg \& Woolworth, 2001; McLaughlin \& Talbert, 2001; Rozenholtz, 2001); but, these efforts have competition. There is a tendency to focus some professional time and attention on current "hot" topics that may be characterized by narrowness of vision, a focus on one population, or a single issue to the detriment of a broader focus on student achievement. As new trends are highlighted in the context of pre-service teacher preparation, the larger vision of preparing teachers to impact students' learning can be diminished. Cochrane-Smith and Power (2010) identify ten such trends in teacher preparation. While some of these trends incorporate a focus on students' learning, an equal number of emerging trends do not. In a recent research report Henry, Bastien, and Fortner (2011) conclude in their work on new teachers that, "...in light of novice teachers' significant capacity for growth, improving their initial effectiveness as rapidly as possible seems to us to offer the greatest promise for improving student performance" (p. 279). Our conceptual diagram (Figure 2) provides a broader vision of strategies that extend teachers' focus on student learning/performance to all levels of their careers 
(Timmons, 2006; Jordan \& Stanovich, 2004). Additionally, our diagram has the potential to become an overarching framework that can provide filters to direct time, resources, and professional energy to the most promising aspects of the complex dynamics of student learning in schools. This focus will direct Stage 2 of our study.

During Stage 2 of this project, researchers will partner with several school boards that have coterminous faculties of education. We intend to examine the pre-service programs to determine the extent to which pre-service courses are addressing the elements conceptualized to contribute to the shift in teachers' professional focus. This aspect of the research will be addressed by examining course outlines against an analysis framework reflective of the diagram (Figure 2), and by interviewing a sample of faculty to determine their beliefs and instructional goals within the pre-service program. Hiring practices within coterminous boards will be examined. In-service opportunities within the boards will be investigated to determine their contribution to the elements. Novice teacher induction and mentoring programs will be examined for their goals and activities to align these with the conceptual elements that contribute to the shift in professional focus. Finally, teachers in later years of their career will be interviewed to determine the nature of the supports they seek and acquire to extend their career trajectories, and the extent of alignment of these trajectories to the elements of the shift in focus will be examined.

During Stage 3, the final stage of this project, researchers will work with coterminous faculties of education and school boards to plan for the alignment and improvement of teacher preparation supports. Alignments and improvements are anticipated to have an impact on student learning. This is the goal of school improvement. We anticipate that our research will support ways that professionals go about their practice in the future. In the words of Coulter (2010), this research should "restore the logic chain of program theory" in relation to the alignment of teacher education and professional growth. This research agenda provides a fit between the conceptual diagram that describes elements of teachers' professional shift in focus and the professional growth continuum for teachers. It has the potential to provide direction for reasonable action related to the examination of a consistent message about what is valued in teachers' professional growth (Strauss \& Corbin, 1990). While the characteristics of effective teachers, as measured by student learning, are identified in the diagram (Figure 2) that is the focus of this paper, we cannot ensure that every teacher who demonstrates evidence of these characteristics will maintain a focus on students' learning. We are, however, suggesting that this diagram is a starting point for further research into this complex dynamic. This diagram will allow us to promote professional development that is focused on constructivist and situational theories rather than on behavioural approaches that may currently be uncovered through traditional teacher hiring practices (Van Driel, \& Berry, 2012; Borko et al., 2010).

Instruments and processes to help examine the continuum of teacher growth have now been developed for the Stage 2 of this research. We are currently working with several school boards to determine hiring practices as they may relate to aspects of a new teacher's tendency to focus efforts on improving students' learning. The consistency of underlying conceptions for each stage of the process of teacher development will be examined. This research can help school boards determine how to address the hiring of new teachers in the most effective way to ensure that they hire teachers with a learner- 
centered focus. It can also help Faculties of Education reexamine their programs to determine elements that might be refined or added to their program to make pre-service teachers aware of the critical shift required in their professional focus as they teach. It is our hope that Figure 2, Professional Shift Theory (pst), will become a schema for visioning by those who provide services to the profession of teaching and those who wish to focus on student learning as the central element of pre-service program renewal and school improvement. In the words of Mitchell and Sackney (2009), "Awareness is the beginning but it can't be the end, so it is critical that there are strategies in place for people to move forward" (p. 90). 


\section{References}

Abbott, A. (1991). The order of professionalism: An empirical analysis. Work and Occupations, 355-384.

Allen, M.J. (2004). Assessing academic programs in higher education: Bolton: Ander Publishing Company, Inc.

Amos, D. (2012). Ohio puts teachers on notice. Retrieved from Cincinnati.com http://news.cincinnati.com/article/20120304/NEWS0102/303050024/Ohio-putsteachers-notice)

Borko, H., Jacobs, J., \& Koellner, K. (2010). Contemporary approaches to teacher professional development. In P.L. Peterson, E. Baker, \& B. McGaw (Eds.), Third international encyclopedia of education, (Vol. 7, pp. 548-556). Amsterdam, NL: Elsevier.

Boyatziz, R.E. (1982). The competent manager: A model for effective performance. New York: John Wiley \& Sons, Inc.

Breaux, A. \& Whitaker, T. (2006). Seven simple secrets: What the best teachers know and do. Larchmount, New York: Eye on Education.

Brundrett, M. \& Silcock,P. (2002). Achieving competence, success, and excellence in teaching. Psychology Press. Taylor and Francis Group.

Charney, R. (2002). Teaching children to care: Classroom management for ethical and academic growth, $K-8$. Northeast Foundation for Children, Inc.

Chen, H.T., Rossi, P.H. (1983). Evaluating with sense. Evaluation Review, 7, 283-302.

Clarke, D. \& Hollingsworth, H. (2002). Elaborating a model of teacher professional growth. Teaching and Teacher Education, 18(8), 47-967.

Cochran-Smith, M., Gleeson, A., \& Mitchell, K. (2010). Teacher education for social justice. What's pupil learning got to do with it? Berkeley Review of Education. California: eScholarship.

Cochran-Smith, M., \& Power, C. (2010). New direction in teacher preparation. Educational Leadership, 67(8), 6-13.

Conati, C., (2002). Probabilistic assessment of user's emotions in educational games. Journal of Applied Artificial Intelligence, 16, 555-575.

Coulson, M., (2004). Attributing emotion to static body postures: Recognition accuracy, confusion, and viewpoint dependence, Journal of Nonverbal Behavior, 28, 117 139. 
Coulter, S. (2010). Using survey data to restore program theory of professional learning communities. AERA, Denver, CO.

Craig, S.D., C. Graesser, J. Sullins and B. Gholson (2004). Affect and learning: An exploratory look into the role of affect in learning. Journal of Educational Media, 29, 241-250.

Creswell, J.W. (2002) Educational research: Planning, conducting, and evaluating quantitative and qualitative research. Upper Saddle River, N.J: Merrill Prentice Hall.

Darling-Hammond, L. (1992). Doing what matters most: Investing in quality teaching. National Commission on Teaching and America's Future. Kutztown, PA: Kutztown Distribution Center.

Darling-Hammond, L. \& Goodwin, A.L. (1993). Progress towards professionalism in teaching. In G. Cawelti (Ed.), Challenges and achievements of American education: The 1993 ASCD yearbook (pp.19-52). Alexandria, VA: Association for Supervision and Curriculum Development.

Darling-Hammond, L. \& Snyder, J. (1992). Framing accountability: Creating learnercentered schools. In A. Liebermann (Ed.), The changing contexts of teaching $\left(91^{\mathrm{st}}\right.$ yearbook, pp.11-36). New York: Teachers College Press.

Davies, A. (2012). Transforming barriers to assessment for learning. Saskatoon. Connections Publishing Institute.

Day, C., (2004). A passion for teaching. New York: Routledge.

Donaldson, S.I. (2007). Program theory-driven evaluation science: Strategies and applications. Mahwah, NJ: Erlbaum.

Earl, L. (2006). Rethinking classroom assessment with purpose in mind. Retrieved April 27, 2006 from http://resources.curriculum.org/secretariat/april27.shtml

Earl, L. (2008). Growing success. Toronto: Queen's Printer of Ontario.

Elmore, R.F., Peterson, P. \& McCarthey, S. (1996). Restructuring the classroom: Teaching, learning, and social organization. San Francisco: Jossey-Bass.

Fenwick, T.J. (2001). Fostering teachers' lifelong learning through professional growth plans: A cautious recommendation for policy. Paper presented at the PanCanadian Education Research Agenda Symposium, Quebec City.

Garmston, R.J. (1998). Becoming an expert teacher (Part 1). Journal of Staff 
Development, 19 (1).

Grossman, P., Wineburg, S. \& Woolworth, S. (2001). Toward a theory of teacher community. Teachers College Record, 103(6), 942-1012.

Hatt, B.E. (2005). Pedagogical love in the transactional curriculum. Journal of Curriculum Studies 37(6), 671-688.

Hatt, B. E. (2008). Heart in teaching: Attending the pathic. Köhn, DE: Lambert Academic Press.

Henry, G. T., Bastian, K.C., \& Fortner, C.K. (2011). Stayers and leavers: Early-career teacher effectiveness and attrition. Educational Researcher 40(6), 271-280.

Hobbs, L. (2012). Examining the aesthetic dimensions of teaching: Relationships between teacher knowledge, identity and passion. Teaching and Teacher Education, Elsevier.

Jordan, A. \& Stanovich, P.(2004). The beliefs and practices of Canadian teachers about including students with special needs in their regular elementary classrooms. Exceptionality Education Canada, 14(2 \& 3), 25-46.

Kameenui, E., Carnine, D. (1998). Effective teaching strategies that accommodate diverse learners. Prentice-Hall Inc.

Kennedy, M. (2011). Attribution error and the quest for teacher quality. Educational Researcher, 39(8). 591-598.

Killen, R., (2006). Effective teaching strategies (4 ${ }^{\text {th }}$ Edition). Australia: Thomson Social Science Press.

Leat, D. (1993). Competence, teaching, thinking and feeling. Oxford Review of Education, 19 (4).

Le Cornu, R. \& Ewing, R.(2008). Re-conceptualizing professional experiences in preservice teacher education: Reconstructing the past to embrace the future. Teaching and Teacher Education, 24 (7), 1799-1812.

Little, J.W. (1990). The persistence of privacy: Autonomy and initiative in teachers' professional relations. Teachers College Record, 91, 509-536.

Meador, D. (n.d.).Qualities of effective teachers: Ten qualities of effective teachers. Retrieved August 11, 2012 from http:// teachingabout.com/od/pd/a/Qualities-Of-An-Effective Teacher.htm

Maynes, N. (2012). Examining a false dichotomy: The proper place of direct 
instruction and problem-solving approaches in today's classrooms. International Journal of Business and Social Science (IJBSS), 3(7).

Maynes, N., \& Hatt, B. E. (2011). Grounding program change in students' learning: A model for the conceptual shift in thinking that will support valuable program change in response to faculty of education reviews. In T. Falkenberg \& H. Smits (Eds.), The question of evidence in research in teacher education in the context of teacher education program review in Canada (2 vols.). Winnipeg, MB: Faculty of Education of the University of Manitoba.

Maynes, N. \& Julien-Schultz, L. (2012). Do visual frameworks for professional reflection on planning and lesson delivery impact the range of reflections? In F. Doynan (Ed.), Research on Teacher Education and Training. Athens, Greece: University of Athens.

Maynes, N., Julien-Schultz, L. \& Dunn, C. (2010). Modeling and the gradual release of responsibility: What does it look like in the classroom? Brock Journal, 19(2), 6577.

Maynes, N. \& Straub, J. (2010). Social studies: Innovative approaches for teachers. Toronto: Pearson Education.

McLaughlin, M.W. \& Talbert, J.E. (2001). Professional communities and the work of high school teaching. Chicago: University of Chicago.

Mitchell, C. \& Sackney, L. (2009). Sustainable improvement: Building learning communities that endure. Rotterdam. Sense Publishers.

Noddings, N. (2002). Educating moral people: A caring alternative to character education. VT: Teachers College Press.

Noell, G.H. \& Burns, J.L. (2006). Value-added assessment of teacher preparation: An illustration of emerging technology. Journal of Teacher Education, 57, 37-50.

Orlich, D., Harder,R., Callahan, R., Trevisan, M., \& Brown, D. (2010). Teaching strategies to guide effective instruction ( $9^{\text {th }}$ Edition). Boston, MA: Wadsworth Cengage Learning.

Pecheone, R., \& Chung, R. (2006). Evidence in teacher education: The performance assessment for California teachers (PACT). Journal of Teacher Education, 57(1), 22-36.

Phelan, A. (2009). A new thing in an old world: Instrumentalism, teacher education, and responsibility. In F. Benson and C. Riches (Eds.), Engaging in conversation about ideas in teacher education. New York: Peter Land Publishing, Inc. 
Rogers, P.J., Hacsi, T. Petrosino, A. \& Huebner, T. (Eds.). Program theory in evaluation: Challenges and opportunities. New Directions for Evaluation, No.87. San Francisco: Jossey-Bass.

Roorda, D.L., Koomen, M.Y., Spilt, J. L. \& Oort, F. J. (2011). The influence of affective teacher-student relationships on students' school engagement and achievement: A meta-analytic approach. Review of Educational Research 81(4), 493-529.

Rozenholtz, S.J. (2001). Teachers' workplace: The social organization of schools. New York: Teachers College Press.

Shulman, L.S. (1987). Knowledge and teaching: Foundations of the new reform. Harvard Educational Journal, 57 (1), 1-23.

Strauss, A. \& Corbin, J. (1990). Basics of qualitative research: Grounded theory procedures and techniques. Thousand Oaks: CA. Sage Publications, Inc.

Strathan, D. \& Ware, A. (2001). Achieving success in North Carolina Lighthouse Schools: An analysis of the dynamics of meaningful reform. Chapel Hill: University of North Carolina, Center for School Leadership Development.

Timmons, V. (2006). Impact of a multipronged approach to inclusion: Having all partners onside. International Journal of Inclusive Education, 10, 469-480.

Tomlinson, C.A. (2007). Learning to love assessment, Educational Leadership, 65(4), 813.

Tomlinson, C.A., et al (2009). The parallel curriculum: A design to develop learner potential and challenge advanced learners $\left(2^{\text {nd }}\right.$ ed.). CA: Thousand Oaks, Corwin Press.

Trier, J. (2009). The 400 Blows as cinematic literacy narrative. Teacher Education Quarterly. 34(3), 35-51.

Van Driel, J.H., \& Berry, A. (2012). Teacher professional development focusing on pedagogical content knowledge. Educational Researcher, 41(1).

Vescio, V., Ross, D., \& Adams, A. (2008). A review of research on the impact of professional learning communities on teaching practice and student learning. Teaching and Teacher Education, 24, 80-91. 